\title{
Safety measures taken by Norwegian mothers
}

\author{
Øydis Ueland, Pål Kraft
}

\begin{abstract}
Objectives-To identify predictors of the adoption of safety measures by mothers of 2 year old children.
\end{abstract}

Setting-26 municipalities in the county of Sogn and Fjordane, and four municipalities in the county of Møre and Romsdal in Norway.

Methods-Data was collected by questionnaires mailed to all mothers of 2 year olds in the 30 municipalities (response rate $70.7 \%, n=1233$ ). Information was obtained on socioeconomic variables, the child's injury history, adoption of safety measures, and variables describing mother's health related beliefs (parent health locus of control) and the value of health (health value).

Results-Income, municipality of residence, age of the mother, and marital status were significantly associated with the reported adoption of safety measures. High income and older, married mothers were positively associated with the adoption of safety measures.

Conclusions-The significant effect of income on the adoption of safety measures, underlined by the fact that safety measures were less often adopted by young single mothers, may indicate that the implementation of structural measures such as loan schemes and subsidies, are necessary to increase the adoption of child safety measures. The lack of association between education and social cognitive beliefs, respectively, and the adoption of safety measures, offer less optimism for traditional health education initiatives.

(Injury Prevention 1996; 2: 197-201)

Keywords: safety measures, parental behaviour, income, education.

Department of Health Promotion, National Institute of Public Health, Oslo, Norway $\emptyset$ Ueland

Research Centre for Health Promotion, University of Bergen, Bergen, Norway. P Kraft

Correspondence to: Øydis Ueland, National Institute of Public Health, PO Box 4404 Torshov, N-0403 Oslo, Norway. measures, supervise, or educate their children to avoid risk situations. As far as young children are concerned, parents tend to overestimate the child's maturity. ${ }^{5}$ Because constant supervision is unrealistic, the adoption of safety measures seems the most appropriate strategy for young children. ${ }^{6}$ In particular, the adoption of passive safety measures in the home or home environment seem most likely to be beneficial..$^{7-9}$

For young children the avoidance of risk situations and adoption of safety measures depends on the behaviour of the parents. Thus, parents represent an important target group for health promotion initiatives in this field, along with teachers, health personnel, architects, manufacturers, and others. Consequently, in Norway as in many other countries, major health education efforts have been directed towards parents to prevent child injuries. ${ }^{9-11}$ However, a number of evaluation studies seem to indicate a limited effect of such initiatives. ${ }^{6}$ One explanation for these disappointing findings may be related to programme failure, ${ }^{12}$ that is that the initiatives did not influence the most important determinants of parents' safety behaviours. This may be ascribed to the fact that relatively little research has been undertaken to identify such behavioural determinants. ${ }^{6}$

The present study described data collected from a group of mothers of children aged 2 years and resident in the western part of Norway $(n=1233)$. The study had two main purposes. First, to provide estimates of the proportion of parents who had adopted a number of specific safety measures, and second, to identify predictors for parents adoption of such safety measures. Three groups of predictors were of particular interest. It was hypothesised that the proportion of parents who had adopted specific safety measures would differ between municipalities due to local injury prevention initiatives. It was also hypothesised that the adoption of child safety measures would be positively associated with the mothers' economic and educational resources. ${ }^{913-15}$ The last issue to be examined related to: (1) the value placed on health, ${ }^{16}$ and (2) parents' beliefs about their child's health, as measured by the parent health locus of control (PHLOC) scales, ${ }^{16}$ and the value placed on health. ${ }^{17}$ It is argued that health control beliefs will motivate health behaviours only if the outcome of the variable is highly valued by the person..$^{18} \mathrm{We}$ believe that the parents' experience of control over their child's health will be positively associated with their adoption of safety measures. We also expected to find a significant direct effect of health value as well as a significant interaction effect of control beliefs and health value upon the adoption of safety measures. 


\section{Methods}

SETTINGS AND STUDY POPULATION

The present study reports on data from a postal survey conducted during fall 1993 and winter 1994 in 26 municipalities in the county of Sogn and Fjordane (population 107200 ) and four municipalities (population 18500) in the county of Møre and Romsdal. The municipalities varied in population size from 1124 to 10399 . The study population consisted of parents of all children who reached the age of 2 years during 1993.

\section{QUESTIONNAIRE AND DATA COLLECTION}

The questionnaire was developed on the basis of other surveys, ${ }^{19}$ peer review, and pilot testing. A letter containing a questionnaire and a preaddressed, stamped return envelope was mailed. The mother (or stepmother) of the child was asked to fill in the questionnaire and if she was unavailable, the father (stepfather) or other primary caretaker was asked to do so. Two reminders were mailed to nonresponders. The sampling procedures, as well as the collection and registration of data, were handled by Statistics Norway.

\section{MEASURES}

The respondents filled in a self administered questionnaire that took approximately 15 minutes to complete. It included 18 questions about specific safety measures, selected according to which measures have been promoted by the authorities and non-governmental organisations. Fourteen were passive measures (shown in table 2). For each safety measure the mothers reported whether or not it was adopted, or not revelant. A sum of adoption of passive measures was calculated, creating an index. This index had a normal distribution (passive safety measures, range -14 to +14 , mean $2 \cdot 83$, SD 4.09). Four items (shown in table 3) covered the use of safety equipment. The mothers reported how often each was used when certain behaviours were performed (for example wearing a helmet) on a five point scale: 'always' to 'never'. A score was calculated by summing the responses (active safety measures, range -12 to +8 , mean $5 \cdot 45$, SD $2 \cdot 25$ ). This index had a skewed distribution. The correlation (Spearman) between the passive and active indices was $r_{s}=0.22(\mathrm{p}<0.001)$.

\section{INDEPENDENT VARIABLES}

The PHLOC items were translated into Norwegian and verified by a translation and back translation procedure. This PHLOC instrument contains 30 items that reflect six subfactors (professional influence, parental influence, child influence, media influence, fate influence, and divine influence) (see Appendix). ${ }^{16}$ Respondents express their degree of agreement or disagreement using a six point Likert scale. Health value was measured by four items, using a seven point Likert scale. ${ }^{17}$ The sociodemographic variables include the parent's age, number of children, marital status, place of residence, length of formal education, and family income. They also reported on whether the child had received medical treatment due to an injury during the last year, and the type of accident that caused the injury.

\section{STATISTICAL ANALYSIS}

One way analysis of variance (ANOVA) was performed to determine if the differences in variations observed in the use of passive safety measures could be ascribed to the independent variables measured. The index measuring the use of active safety measures did not follow a normal distribution, so the Kruskal-Wallis test for non-parametric variables was used. Correlations (Pearson's $r$ and Spearman's $r_{\mathrm{s}}$ ) were used to indicate possible associations between variables. The analysis were performed using SPSS for Windows, release 6.0.

\section{Results}

SAMPLE CHARACTERISTICS

A total of 1833 families of 2 year old children received the questionnaire. The response rate was $70.7 \%$, and of these, $67.3 \%$ (1233) were mothers of the child; only mothers' responses are considered in this study. The characteristics of the study population are shown in table 1.

Table 2 shows that depending on the specific measure, between $26 \%$ and $94 \%$ of the mothers reported that they had adopted different passive safety measures and table 3 shows that over $90 \%$ report that they often or always used the specific safety measures. Tables 4 and 5 show the impact of different predictors on the adoption of passive and active safety measures.

ADOPTION OF SAFETY MEASURES BY PLACE OF RESIDENCE

A one way ANOVA, with the sum-score index on adoption of passive safety measures as the

Table 1 Demographic characteristics of mothers of 2 year old children living in the western part of Norway $(n=1233)$

\begin{tabular}{lc}
\hline Characteristic & No $(\%)$ \\
\hline Age of mother (years) & \\
$19-24$ & $131(10 \cdot 7)$ \\
$25-29$ & $379(31 \cdot 0)$ \\
$30-34$ & $450(36 \cdot 8)$ \\
$35-39$ & $206(16 \cdot 8)$ \\
$>40$ & $58(4 \cdot 7)$ \\
Education & \\
Secondary school & $83(6 \cdot 7)$ \\
$\quad \leqslant$ Years high school & $311(25 \cdot 3)$ \\
3 Years high school & $423(34 \cdot 4)$ \\
$<4$ Years university & $262(21 \cdot 3)$ \\
$\geqslant 4$ Years university & $151(12 \cdot 3)$ \\
Annual family income (NOK) & \\
$<200000$ & $372(31 \cdot 3)$ \\
$200000-299$ 999 & $443(37 \cdot 3)$ \\
$\geqslant 300000$ & $373(31 \cdot 4)$ \\
No of children in the household & \\
1 & $303(24 \cdot 7)$ \\
2 & $503(41 \cdot 0)$ \\
3 & $309(25 \cdot 2)$ \\
$\geqslant 4$ & $112(9 \cdot 2)$ \\
\hline
\end{tabular}


Table 2 Proportion ( $\%$ ) of mothers reporting adoption of specific passive safety measures $(n=1233)^{\star}$; figures in parentheses are number of responses

\begin{tabular}{|c|c|c|c|}
\hline \multirow[b]{2}{*}{ Element in questionnaire } & \multicolumn{3}{|c|}{ Adopt passive safety measures } \\
\hline & $\overline{Y e s}$ & No & Not relevant \\
\hline $\begin{array}{l}\text { Are all indoor stairs supplied with handrails? } \\
\text { Are the steps of all indoor stairs of the closed type? } \\
\text { Do all indoor stairs have a safety barrier at the top? } \\
\text { Do all indoor stairs have a safety barrier at the } \\
\text { bottom? }\end{array}$ & $\begin{array}{l}78(948) \\
45(545) \\
49(591) \\
20(245)\end{array}$ & $\begin{array}{l}8(94) \\
39(463) \\
31(371) \\
57(692)\end{array}$ & $\begin{array}{l}15(182) \\
16(193) \\
21(253) \\
22(269)\end{array}$ \\
\hline $\begin{array}{l}\text { Do all windows have childproof safety catches? } \\
\text { Do you have a bathing rug in the bathtub/shower } \\
\text { cabinet? }\end{array}$ & $\begin{array}{l}72(885) \\
60(742)\end{array}$ & $\begin{array}{l}25(308) \\
37(452)\end{array}$ & $\begin{array}{l}2(29) \\
3(34)\end{array}$ \\
\hline $\begin{array}{l}\text { Do you have slip-free floor covering in the } \\
\text { bathroom? }\end{array}$ & $27(322)$ & $71(865)$ & $2(24)$ \\
\hline $\begin{array}{l}\text { Are plastic bags kept in a safe place away from } \\
\text { the child? }\end{array}$ & $44(533)$ & $56(685)$ & $0(3)$ \\
\hline $\begin{array}{l}\text { Do you have a lockable medicine cabinet? } \\
\text { Are there plastic stoppers in all unused electric } \\
\text { outlets? }\end{array}$ & $\begin{array}{l}49(598) \\
56(689)\end{array}$ & $\begin{array}{l}41(499) \\
43(525)\end{array}$ & $\begin{aligned} & 10(124) \\
& 1(11)\end{aligned}$ \\
\hline $\begin{array}{l}\text { Does the electric cooker have top guards (so } \\
\text { kettles cannot be reached and overturned)? }\end{array}$ & $46(567)$ & $53(651)$ & $1(11)$ \\
\hline $\begin{array}{l}\text { Does the oven door have low surface temperature } \\
\text { or guard? }\end{array}$ & $69(851)$ & $31(375)$ & $0(3)$ \\
\hline $\begin{array}{l}\text { Are detergents kept in an inaccessible place away } \\
\text { from the child? }\end{array}$ & $86(1052)$ & $14(173)$ & $0(2)$ \\
\hline $\begin{array}{l}\text { Are matches kept in an inaccessible place away } \\
\text { from the child? }\end{array}$ & $94(1154)$ & $6(74)$ & $0(3)$ \\
\hline
\end{tabular}

«The number of mothers does not add up to 1233 as some mothers did not answer the question.

dependent variable and municipality as independent variable, showed a significant variation between municipalities $(p=0.001$, $\mathrm{F}=2 \cdot 021, \mathrm{df}=29,1099)$. The Kruskal-Wallis test for non-parametric variables with the sumscore index on active safety measures as the dependent variable against the municipalities of residence, showed a significant difference in variation $(p=0.03)$. This was due solely to a difference between municipalities in the use of bicycle helmets.

ADOPTION OF SAFETY MEASURES BY SOCIODEMOGRAPHIC FACTORS

Education was not a significant factor in the adoption of either passive or active safety measures. Income, on the other hand, accounted for significant differences on the passive index $(\mathrm{p}=0.03, \mathrm{~F}=3.468$, $\mathrm{df}=2,1090$ ). The use of active safety measures, as measured by the active sum-score index, were also significantly associated with income $(p=0.004)$. Mother's age was a significant predictor, with older mothers more likely to adopt passive safety measures than those 19-24 years. Age was not a predictor, however, for the use of active safety measures. Marital status was a significant predictor on the passive sum-score index $(\mathrm{p}=0.002, \mathrm{~F}=4.933$, $\mathrm{df}=3,1124)$. Both married mothers and those living together had a significantly higher use of passive safety equipment as compared with single, unmarried mothers. Marital status was not a predictor for the use of active safety measures.

ANOVA with passive index as the dependent variable and the independent variables income, age, and marital status (values; single and married/living together) showed that adoption of passive safety measures was significantly associated with an interaction between age and marital status $(p<0.0001$, $\mathrm{F}=4.778, \quad \mathrm{df}=7,1115)$. Older, married mothers had adopted significantly more passive safety measures than young, unmarried mothers.

\section{ADOPTION OF SAFETY MEASURES BY PHLOC SCALES}

There was a weak but significant correlation between use of passive safety measures and the professional influence factor from the PHLOC scales $(p=0.04, r=-0.0634)$. Another weak, significant negative correlation was also found between the use of active safety measures and the divine influence factor $(p=0.03$, $r=0.0636$ ). No other factor nor any single item were significantly associated with the passive safety measures, and the health value index did not correlate significantly with either the passive or active indices.

\section{ADOPTION OF SAFETY MEASURES BY INJURY} HISTORY

One hundred and nine mothers reported that their child had been treated for one or more injuries during 1993. Not surprisingly in these families the probability that the mothers reported using active measures was significantly increased $(p=0.03)$.

\section{Discussion}

This study shows that the adoption of child safety measures is positively associated with the mother's economic situation. Income was also

Table 4 Predictors for mother's adoption of passive safety measures $\star$

\begin{tabular}{lrrl}
\hline Independent variable & $F$ value & \multicolumn{1}{l}{$d f$} & $p$ Value \\
\hline Municipality & 2.0213 & 29,1099 & 0.001 \\
Income & 3.4678 & 2,1090 & 0.032 \\
Education & 1.2911 & 4,1121 & NS \\
Age group & 4.9334 & 4,1118 & $<0.001$ \\
Marital status & 4.9331 & 3,1124 & 0.002 \\
Injury to child treated by & 0.6823 & 1,1103 & NS \\
$\quad$ physician & & 2,1126 & $\mathrm{NS}$ \\
No of injuries in child & 1.3353 & 2,1126 & \\
\hline
\end{tabular}

«The test performed was one way ANOVA.

Table 3 Proportion (\%) of mothers reporting adoption of specific active safety measures $(n=1233)^{\star}$; figures in parentheses are number of responses

\begin{tabular}{|c|c|c|c|c|c|c|}
\hline \multirow[b]{2}{*}{ Element in questionnaire } & \multicolumn{6}{|c|}{ Adopt active safety measures } \\
\hline & Never & Seldom & Once in a while & Often & Always & Not relevant \\
\hline $\begin{array}{l}\text { Is the child properly fastened in a child safety seat when riding in a car? } \\
\text { Does the child wear a bicycle helmet when riding a bicycle? } \\
\text { Does the child wear a life jacket in small boats? } \\
\text { Does the child wear reflectors when s/he is outside after dark? }\end{array}$ & $\begin{array}{l}0 \cdot 1(1) \\
2 \cdot 3(28) \\
0 \cdot 2(2) \\
0 \cdot 8(10)\end{array}$ & $\begin{array}{l}0 \cdot 2(2) \\
0.7(8) \\
0 \cdot 2(2) \\
1 \cdot 2(15)\end{array}$ & $\begin{array}{l}0.2(2) \\
2 \cdot 5(30) \\
0.6(7) \\
3 \cdot 9(48)\end{array}$ & $\begin{array}{l}3 \cdot 7(45) \\
5 \cdot 8(71) \\
2 \cdot 8(34) \\
16 \cdot 1(196)\end{array}$ & $\begin{array}{l}95 \cdot 2(1172) \\
53 \cdot 2(647) \\
60 \cdot 8(744) \\
59 \cdot 7(729)\end{array}$ & $\begin{array}{l}0 \cdot 7(9) \\
35 \cdot 5(432) \\
35 \cdot 5(434) \\
18 \cdot 3(223)\end{array}$ \\
\hline
\end{tabular}

*The number of mothers does not add up to 1233 as some mothers did not answer the question. 
Table 5 Predictors for mother's adoption of active safety measures *

\begin{tabular}{lrrll}
\hline Independent variable & $\chi^{2}$ & $d f$ & $p$ Value & Rank: lowest, highest \\
\hline Municipality & 44.75 & 29 & 0.031 & 328,753 \\
Income & 10.88 & 2 & 0.004 & 538,615 \\
Education & 4.48 & 4 & NS & 567,632 \\
Age group & 3.09 & 4 & NS & 544,617 \\
Marital status & 1.60 & 3 & NS & 546,627 \\
Injury to child treated by physician & 5.02 & 1 & 0.025 & 584,661 \\
No of injuries in child & 6.10 & 2 & 0.047 & 593,743 \\
\hline
\end{tabular}

*The test performed was Kruskal-Wallis test for non-parametric variables.

positively associated with the adoption of both passive and active safety measures, and these associations hold even after controlling for the mother's level of education. Consequently, these findings support those of previous studies showing income to be a predictor of the adoption of safety measures. ${ }^{131420}$ This influence of economic resources was expected because safety measures in many cases involves the installation of equipment or its purchase therefore representing an economic burden. ${ }^{14}$

Surprisingly, however, no support was obtained for the hypothesised effect of education on the adoption of safety measures. Although the research literature seems to be inconclusive, ${ }^{6}$ a positive association between the parent's education and adoption of safety measures was expected because some studies indicate that parents with higher levels of socioeconomic status tend to have more accurate perceptions of injury risks. ${ }^{15}$ Furthermore, no, or only weak associations were observed between social cognitive variables on the PHLOC scales and the use of safety measures, even after controlling for interaction between PHLOC and health value. Several studies indicate that the PHLOC instrument is psychometrically sound (unpublished data), ${ }^{16}$ thus a methodological explanation seems unlikely. Consequently, the effect of income on the adoption of safety measures may be causal, resulting from the financial ability to buy and install safety equipment. The present study suggests that in searching for predictors of the adoption of safety measures, economic and educational resources should be treated as methodologically and theoretically separate constructs.

The data presented also show that the adoption of passive safety measures was associated with the mother's age and marital status. Specifically, young single mothers reported using passive safety measures less often than older, married mothers. These effects remain even when the effect of income is controlled for.

These findings may be interpreted in several ways. First, they seem to confirm previous studies that have reported that less privileged families less often adopt safety measures. ${ }^{131420}$ Second, they may indicate that, in addition to having fewer financial resources to buy safety equipment, young single mothers less often live in modern accommodation. Several of the passive safety measures included in the study, such as having a slip-free floor covering in bathrooms and closed steps, are usually found in newly built houses but not in older houses. The cost of installing such devices in older buildings amounts to several thousand Norwegian crowns (NOK).
The positive associations between income and safety measures observed at the individual level are supported by the aggregate data. These showed that the municipality with the lowest score on a mother's use of active safety measures, also scored very high or highest on official statistics in terms of such general social indicators as the proportion of single caretakers, the proportion of persons living on social benefit, the incidence of child care cases, and the level of unemployment. ${ }^{21}$ In contrast, the data showed a high level of adoption of passive safety measures in a municipality that scored high on average level of income. Nevertheless, it is noteworthy that no differences in the adoption of either active or passive safety measures could be traced to differences in injury prevention initiatives at the municipal level.

We set out to present epidemiological data on the adoption of safety measures in a group of Norwegian mothers of young children. As has been confirmed in other Norwegian studies, ${ }^{19}$ relatively high proportions of mothers reported to have adopted a number of specific measures, especially the active measures included in the study. This may partly be related to the fact that, for example, the use of seat belts for children in cars is mandatory. On the other hand, a number of the passive safety measures were less often adopted. It was, for example, surprising that only $47 \%$ and $61 \%$ of the mothers reported to have installed top guards on cookers and barriers at the top of the stairs, respectively. The adoption of these measures has been advocated in a number of national campaigns involving the mass media and the distribution of brochures in health care units. Furthermore, it was disappointing that only $44 \%$ of the mothers reported keeping plastic bags in a safe place despite the fact that stories about children who have been suffocated by these bags are well reported by the media, highlighted in health education materials, and that this is a cost-free measure.

One possible limitation of the study is its reliance on self reported behaviours. Because the information given by the mothers was not verified, social desirability might have influenced the number of safe behaviours reported. Others have found that mothers of children tend to report safer behaviour than actually observed. ${ }^{22}$ Findings from other Norwegian studies, however, show self reporting practices of approximately the same magnitude as in this study, ${ }^{19}$ indicating that our results are fairly representative of reporting practices among parents.

Another limitation of the study is the selection of study populations based on residence in one geographic area. Although the high response rates suggest that the results reflect the behaviours of mothers in the study area, the results should be applied with caution to mothers living in other areas.

\section{IMPLICATIONS FOR PREVENTION}

A number of studies have indicated the limited effects of health education initiatives to prevent child injuries. ${ }^{6}$ One possible explanation is 
programme failure, which may in turn be related to a lack of knowledge about the behavioural determinants of safety behaviours. ${ }^{6}$ The present study does not rule out this explanation. However, the fact that neither the variables reflecting the parent's health control beliefs, nor education, were identified as important predictors, may indicate that only a limited effect can be expected from isolated health education efforts. The significant effect of income on the reported adoption of safety measures, underlined by the fact that measures were less often adopted by young single mothers, suggest that the implementation of structural measures, such as loan schemes and subsidies, should be considered as an additional strategy to more traditional health education initiatives. Thus, at least as far as the adoption of rather expensive safety measures are concerned, price subsidies and legislation that requires certain standards when houses are built, must be considered. Such measures may be particularly beneficial in levelling out differences in the incidence of child injuries between social groups.

\section{Appendix}

\section{Subfactors of the PHLOC scales*}

PROFESSIONAL INFLUENCE

1. Health professionals keep my child from getting sick.

3. My child can avoid illness with regular professional care.

5. Having regular contact with a physician is the best way for my child to avoid illness.

10. Only trained health professionals can influence my child's health.

21. Health professionals control my child's wellbeing.

PARENTAL INFLUENCE

2. I have the ability to influence my child's wellbeing.

13. I can do a lot to prevent my child from getting hurt.

18. I can do a lot to prevent my child from getting sick.

20. The things I do at home with my child are an important part of my child's wellbeing.

24. My child's safety depends on me.

26. I can do a lot to help my child stay well.

29. I can do a lot to help my child be strong and healthy.

CHILD INFLUENCE

4. My child is in control of his/her own health.

9. My child is the one who determines his/her own wellbeing.

15. My child's safety depends mostly on what my child does.

17. My child can decide to live a safe and healthy life.

25. My child can do a lot to avoid getting sick.

28. To a large degree my child can determine his/her own health.

MEDIA INFLUENCE

6. What my child sees in TV commericals can affect my child's health.

8. Some of the comic books around today can affect my child's health.

14. What my child sees in TV programmes can affect my child's health.

22. Magazines my child reads influence his/her wellbeing.
FATE INFLUENCE

7. Whether my child avoids injury is just a matter of luck.

12. Luck plays a big part in determining how healthy my child is.

19. Whether my child avoids sickness is just a matter of luck.

27. My child's good health is largely a matter of good fortune.

30. Whether my child stays healthy or gets sick is just a matter of fate.

DIVINE INFLUENCE

11. God will decide what will happen to my child's health.

16. My child's wellbeing is in God's hands.

23. God will keep my child safe.

*The items' placement in the PHLOC scale are displayed by the number in the front.

1 NOMESKO. Health statistics in the Nordic countries 1992. Copenhagen: Nordisk Medicinal Statistik Komité, 1994 Cop.

2 Official Statistics of Norway. Causes of death 1992. OsloKongsvinger: Statistics Norway, 1994

3 Official Statistics of Norway. Patient statistics 1993. OsloKongsvinger: Statistics Norway, 1995

4 Guldvog B, Thorgersen A, Ueland $\emptyset$. Ulykker, vold og selvpdfort skade. [Injuries, violence and self-inflicted injuries.] Personskaderapport. Oslo: Statens Institutt for Folkehelse, 1992. (SAFH rapport nr 1/92.)

5 Laidman P. Health visiting and preventing accidents to children. London: Child Accident Prevention Trust, 1987. (Research report No 12.)

6 Wortel E, Geus GH de, Kok G, Woerkum C van. Injury control in pre-school children: a review of parental safety control in pre-school children: a review of parental safety Res 1994; 9: 201-13.

7 Tursz A, Lelong N, Crost C. Home accidents to children under 2 years of age. Paediatr Perinat Epidemiol 1990; 4: 408-21.

8 Greensher J. Environmental risks in the industrialized countries. In: Manciaux M, Romer CJ, eds. Accidents in childhood and adolescence. The role of research. Geneva: INSERM, WHO, 1991: 123-32.

9 Glik DC, Greaves PE, Kronenfeld JJ, Jackson KL. Safety hazards in households with young children. $f$ Pediatr Psychol 1993; 18: 115-31.

10 Helsedirektoratet.Abridged version of Red Book 89. Programme of action for prevention of accidents at home, at school ramme of action for prevention of accidents at home, at school Department of Preventive Health Measures, 1989.

11 Thuen F, Klepp KI, Jacobsen R. Aksjon mot hjemmeulykker-ulykkesforebyggende arbeid $\mathrm{i}$ kommunene. Tidsskr Nor Laegeforen 1990; 110: 3387-90.

12 Basch CE, Sliepcevich EM, Gold RS, Duncan DF, Kolbe LJ. Avoiding type III errors in health education program evaluations: a case study. Health Educ $Q$ 1985; 12: 315-31.

13 Gielen AC, Wilson MEH, Faden RR, Wissow L, Harvilchuck JD. In-home injury prevention practices for infants and toddlers: the role of parental beliefs, barriers, and housing quality. Health Educ $O$ 1995; 22: 85-95.

14 Kendrick D. Children's safety in home: parent's possession and perceptions of the importance of safety equipment. Public Health 1994; 108: 21-5.

15 Eichelberger MR, Gotschall CS, Feely HB, Harstad P, Bowman LM. Parental attitudes and knowledge of child safety. Am $\mathcal{F}$ Dis Child 1990; 144: 714-20.

16 De Vellis RF, De Vellis BM, Blanchard LM, Klotz ML, Luchok K, Voyce C. Development and validation of the parent health locus of control scales. Health Educ $Q 1993$; 20: $211-25$.

17 Kristiansen CM. Value correlates of preventive health behaviour. F Pers Soc Psychol 1985; 49: 748-58.

18 Wallston KA. The importance of placing measures of health locus of control beliefs in a theoretical context. Health Educ Res 1991; 6: 251-2.

19 Thuen F. Preventing childhood accidents in the home: parental behaviour to reduce household hazards. Scand $\mathcal{F}$ Psychol 1992; 33: 370-7.

20 Greaves P, Glik DC, Kronenfeld JJ, Jakcson K. Determinants of controllable in-home child safety hazards. minants of controllable in-home

21 Ministry of Social Affairs. Styrings-og informasjonshjulet for helse- og sosialtjenesten i kommunene. Sammenligningstall helse- og sosialtjenesten i kommunene. Sammenligningstall for kommunene 1993. Sogn og Fjordane, Hordaland,
Rogaland (Hefte 4c I-0709/3 B). Oslo: Ministry of Social Rogaland (Hefte 4c I-0709/3 B). Oslo: Ministry of Social Affairs.

22 Wortel E, Geus GH de. Prevention of home related injuries of pre-school children: safety measures taken by mothers. Health Educ Res 1993; 8: 217-31. 